\title{
Synthesis of $\mathrm{PVA} / \mathrm{SiO}_{2}$ Nanofibers by Electrospinning Method for Supercapacitor Separators
}

\author{
Muhamad Nirwan, Heru Setyawan, and Widiyastuti \\ Department of Chemical Engineering, Institut Teknologi Sepuluh Nopember, Surabaya \\ e-mail: sheru@chem-eng.its.ac.id
}

\begin{abstract}
In this research, polyvinyl alcohol (PVA)/silica nanofibers have been synthesized using electrospinning technique. Solutions of sodium silicate $\left(\mathrm{Na}_{2} \mathrm{SiO}_{3}\right)$ in water and PVA flakes were blended and then processed by electrospinning method to obtain PVA/silica nanofibers. The effect of silica concentration on the resulting morphology and diameter of asspun nanofibers were investigated by using scanning electron microscopy (SEM). The electrolyte uptake and retention of the as-spun nanofibers were measured. The silica concentration has an effect on the resulting nanofibers, where an increase in silica concentration resulted in a decrease on the diameter of the fibers. The manufactured nanofibers have an average diameter of 200-300 $\mathrm{nm}$. The electrolyte uptake and retention values are also affected by the concentration of the silica in the electrospun solution, with the electrolyte uptake and retention values decreasing with the increase in silica concentration. The best values obtained are $151 \%$ for electrolyte uptake and $60 \%$ for electrolyte retention, which shows potential for PVA/silica nanofibers as an alternative material for supercapacitor separators.
\end{abstract}

Keywords-Electrospinning, Nanofiber, Separator, Silica, Supercapacitor.

\section{INTRODUCTION}

$\mathrm{T}$ HE increase in fuel costs, pollution, global warming and geopolitical concerns are a number of issues related to the dependence of modern society on fossil fuels. Overcoming this problem is an increasingly important goal that can be achieved through the development of energy storage sources and other technologies. Thus, today there is growing interest in energy storage systems with high energy density and energy. The use of wider renewable sources and better efficiency of the transportation system are two important objectives that must be pursued to overcome this problem [1].

Supercapacitors, also known as double-layer electric capacitors and ultracapacitors, are energy storage devices with short charging and usage times and high electrical efficiency (up to 98\%), high power density and excellent cycle capability (can be refilled to more than 106 times) [2]. The main components of supercapacitors are electrodes, separators, collector and electrolyte currents and supercapacitors can store energy in the form of electrostatic charge accumulation at the electrode/electrolyte interface. The performance of supercapacitors depends on the properties of the main components [3].

One key in the design of high-performance supercapacitors is the choice of separator used. Utilization of high surface area electrodes and high efficiency electrolytes in supercapacitors has led to intense research on separators. Separators used between electrodes in supercapacitors have been made from rubber, plastics, aquagel, formaldehyde polymer polymers, polyolefin films, etc. to prevent conduction of electrons between electrodes, but the separator that has been used so far has a tendency to dry up or break down over time, or exhibit poor ionic conductivity. As a result, there is a need for supercapacitor separators, which are made of high porosity materials which provide minimal resistance to electrolyte ion movement and at the same time, have electronic insulating properties between opposing electrodes [4].

Organic-inorganic hybrid materials are important in various fields because they combine the desired properties of the inorganic phase (thermal stability, stiffness) with the organic phase (flexibility, process capability, elasticity) [5]. In recent years, polymer-silica hybrids with improved thermal and mechanical properties (due to silica components), better flexibility (due to polymer content), and various special properties have attracted much attention for various applications including catalysis, adsorption, pervaporation, sensor, and enzyme encapsulation. The scope and usefulness of this polymer-silica hybrid can be further expanded by transforming it into a nanofiber structure that has a high surface area to volume ratio [6].

Of the various approaches that have been developed to synthesize silica hybrid nanofiber polymers, the one-step electrospinning process has received much attention because of the simplicity of the process, cost effectiveness, and speed of the process [7]. Electrospinning is the technique of forming very fine fibers from viscous liquids (usually a solution or melt polymer) using an electrostatic field [8]. The fiber produced has a high surface area to volume ratio and can be a potential candidate for areas such as membrane technology, drug delivery systems, enzyme immobilization, electronics, and sensors. Combining electrospinning with the sol-gel process provides a way to create one-dimensional nanostructures with an adjustable morphology, size and composition [6].

Silica is one of many materials that have been prepared as nanofiber by electrospinning techniques. Most electrospinning nanofiber silica synthesis begins with the preparation of silica gel sol-gel from tetraethyl ortho silicate (TEOS). The sol-gel process is a wet chemical synthesis technique for making gels, often starting with alkoxide metals undergoing hydrolysis and condensation polymerization reactions to produce oxide gels. The typical sol composition 
The $6^{\text {th }}$ International Seminar on Science and Technology (ISST) 2020

July $25^{\text {th }}$ 2020, Institut Teknologi Sepuluh Nopember, Surabaya, Indonesia

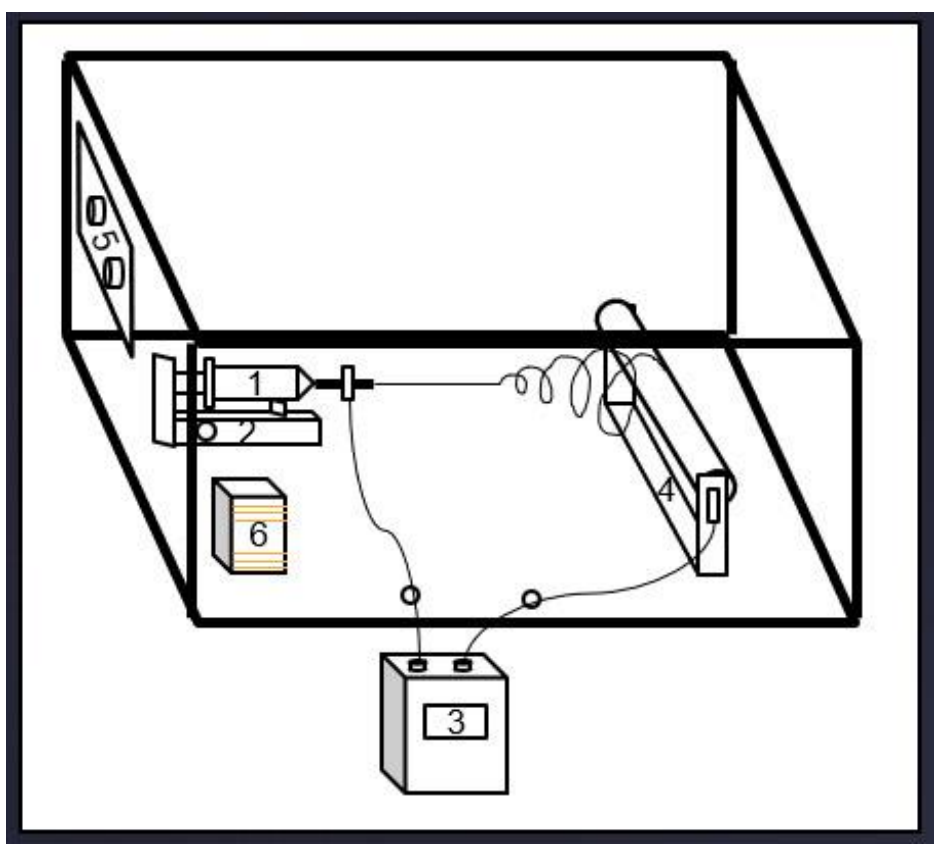

Figure 1. Electrospinning apparatus assembly.

Table 1.

Resulting nanofiber mats from electrospinning process with PVA/silica sol variables

\begin{tabular}{ccc}
\hline \hline Solution composition (w/v) & Results & Remarks \\
\hline PVA 15\%: silica 0,5\% & No nanofiber mats were formed. & 21 gauge needle, flow rate 0,7 ml/hr, $18 \mathrm{kV}$ \\
PVA 15\%: silica 1\% & Thin nanofiber mats with few droplets. & 18 gauge, $0,8 \mathrm{ml} / \mathrm{hr}, 18 \mathrm{kV}$ \\
PVA 15\%: silica 1,5\% & Thin nanofiber mats with few droplets. Fewer mats were formed. & 18 gauge, $0,8 \mathrm{ml} / \mathrm{hr}, 18 \mathrm{kV}$ \\
PVA 15\%: silica 2\% & Thin nanofiber mats with more droplets. & 18 gauge, $0,8 \mathrm{ml} / \mathrm{hr}, 18 \mathrm{kV}$ \\
PVA 15\%: silica 2,5\% & Thin nanofiber mats with more droplets. & 18 gauge, $0,8 \mathrm{ml} / \mathrm{hr}, 18 \mathrm{kV}$ \\
PVA 15\%: silica 3\% & Thin, uneven nanofiber mats with many droplets. & 18 gauge, $0,8 \mathrm{ml} / \mathrm{hr}, 18 \mathrm{kV}$ \\
\hline \hline
\end{tabular}

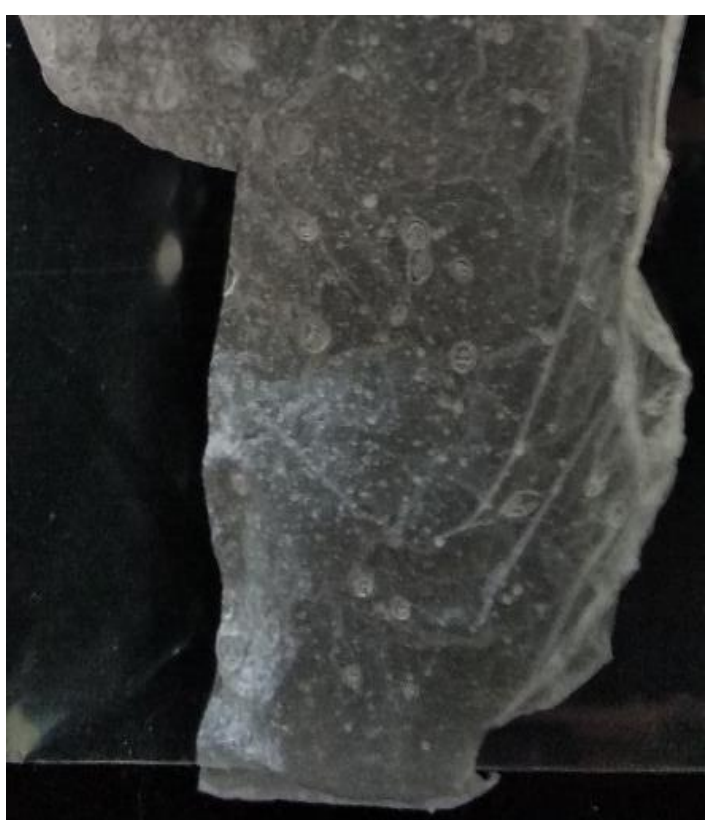

(a)

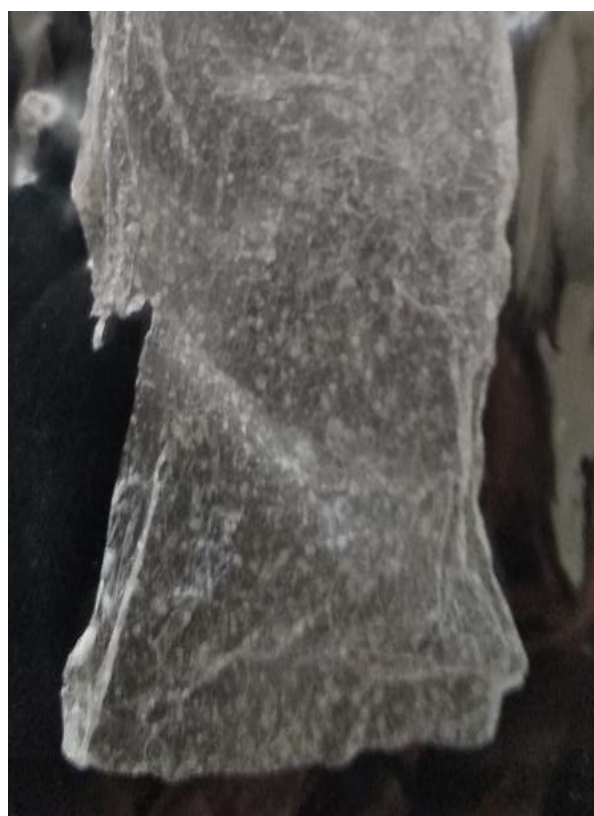

(b)

Figure 2. PVA/silica nanofiber mats with (a) 15:1\% concentration; (b) 15:2\% concentration.

used to make polymer gels consists of TEOS, ethanol, water and an acid or base catalyst [9].

In this study silica in the form of sodium silicate (waterglass) solution is used as a more environmentally friendly silica source, which is then mixed with a carbon polymer in the form of polyvinyl alcohol (PVA). This solution is then processed by the electrospinning method which produces $\mathrm{PVA} /$ silica nanofiber which is expected to be an alternative material for separator applications in supercapacitors.

\section{METHODS}

The aim of this research is to obtain a PVA/silica nanofiber which will be used as a separator component for supercapacitors. In this research the effect of silica 
The $6^{\text {th }}$ International Seminar on Science and Technology (ISST) 2020

July $25^{\text {th }}$ 2020, Institut Teknologi Sepuluh Nopember, Surabaya, Indonesia

Table 2.

Resulting nanofiber mats from electrospinning process with PVA/silicic acid variables

\begin{tabular}{ccc}
\hline \hline Solution composition (w/v) & Results & Remarks \\
\hline PVA 15\%: silicic acid 0,5\% & Thin nanofiber mats with few droplets & 21 gauge needle, flow rate 0,7 ml/hr, 18 kV \\
PVA 15\%: silicic acid 1\% & Thin nanofiber mats with few droplets. & 18 gauge, $0,8 \mathrm{ml} / \mathrm{hr}, 18 \mathrm{kV}$ \\
PVA 15\%: silicic acid 2\% & No nanofiber mats were formed. & 18 gauge, $0,7 \mathrm{ml} / \mathrm{hr}, 18 \mathrm{kV}$ \\
\hline \hline
\end{tabular}

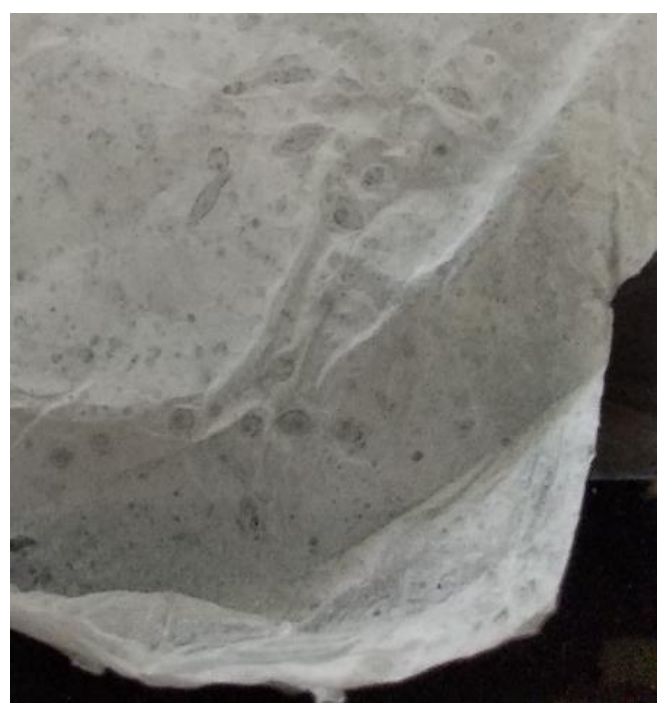

(a)

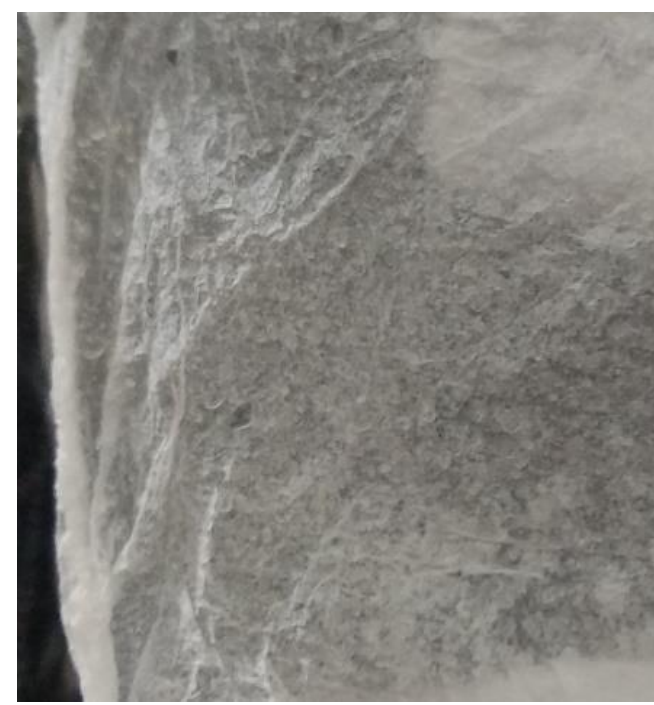

(b)

Figure 3. PVA/silicic acid nanofiber mats with (a) 15:0,5\% concentration; (b) 15:1\% concentration.

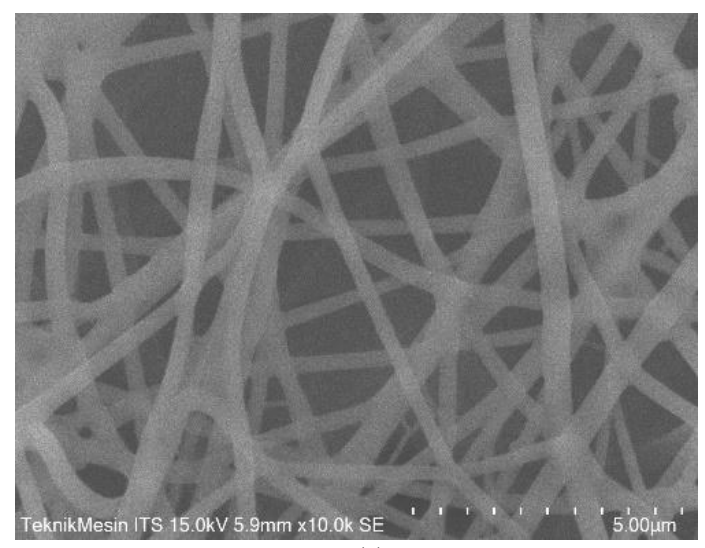

(a)

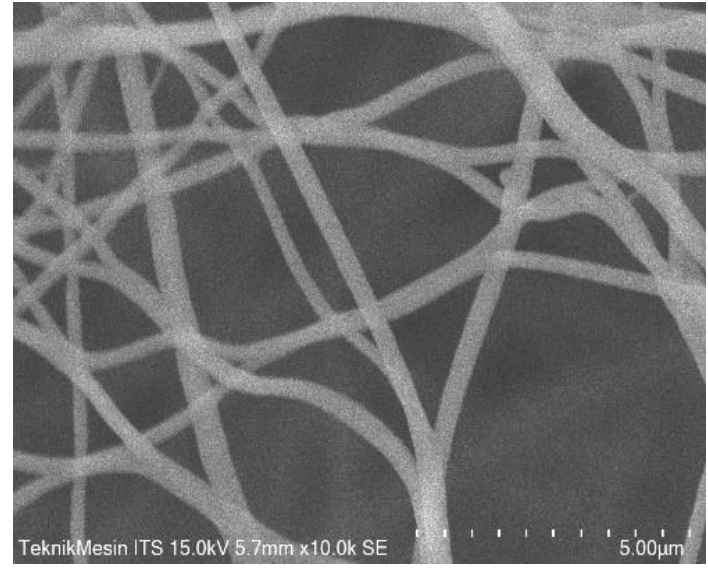

(b)

Figure 4. SEM images of PVA/silica nanofiber mats with (a) 15:1\% concentration; (b)15:2\% concentration.

concentration and form used in the resulting nanofiber is studied. The PVA/silica nanofiber is made with electrospinning method.

\section{A. Materials}

Potassium hydroxide ( $\mathrm{KOH}$; pro analysis grade) was purchased from Merck, PVA was purchased from SigmaAldrich, sodium silicate $(28 \%$, with composition of $\mathrm{SiO}_{2}: \mathrm{Na}_{2} \mathrm{O}=3,3$ ) was obtained from PT. PQ Silicas Indonesia, hydrochloric acid $(\mathrm{HCl} ; 37 \%)$ was purchased from Mallinckrodt, ion exchange resin, demineralized water. All chemicals used were employed without further purification.

\section{B. Synthesis of Silica Nanoparticles}

Sodium silicate was first diluted in demineralized water with a total volume of $100 \mathrm{ml}$ and stirred at temperature of $60^{\circ} \mathrm{C}$ until a homogeneous solution was formed. The solution was then cooled down to room temperature. $100 \mathrm{ml}$ volume of ion exchange resin was used and first rinsed and stirred in demineralized water until the water showed a clear colour.
The resin was later activated by soaking in a $100 \mathrm{ml}$ of $\mathrm{HCl} 1$ $\mathrm{M}$ solution. The soaked resin was stirred at room temperature for 30 minutes. After activation, the resin was separated from the $\mathrm{HCl}$ solution and added to the sodium silicate solution. The resin addition was carried out under strong stirring at room temperature for one hour. The formed silicic acid sol was separated from the resin and titrated by $\mathrm{KOH} 0,1 \mathrm{M}$ solution until it formed the silica sol of desired concentration $(0.5,1,1.5,2,2.5$ and $3 \% \mathrm{w} / \mathrm{v})$ and reached the $\mathrm{pH}$ value of 4.

\section{Electrospinning Process}

PVA solution with concentration of $15 \% \mathrm{w} / \mathrm{v}$ was added to the silica sol under strong stirring at $85^{\circ} \mathrm{C}$ until a homogeneous solution was formed. The formed solution was then loaded into a $50 \mathrm{ml}$ plastic syringe with a 21 gauge stainless steel needle. The flowrate of the solution was set at $0,8 \mathrm{ml} / \mathrm{hr}$ and the voltage was set at $18 \mathrm{kV}$. The distance of the tip of the needle to the aluminium foil collector is $15 \mathrm{~cm}$. 
The $6^{\text {th }}$ International Seminar on Science and Technology (ISST) 2020

July $25^{\text {th }} 2020$, Institut Teknologi Sepuluh Nopember, Surabaya, Indonesia

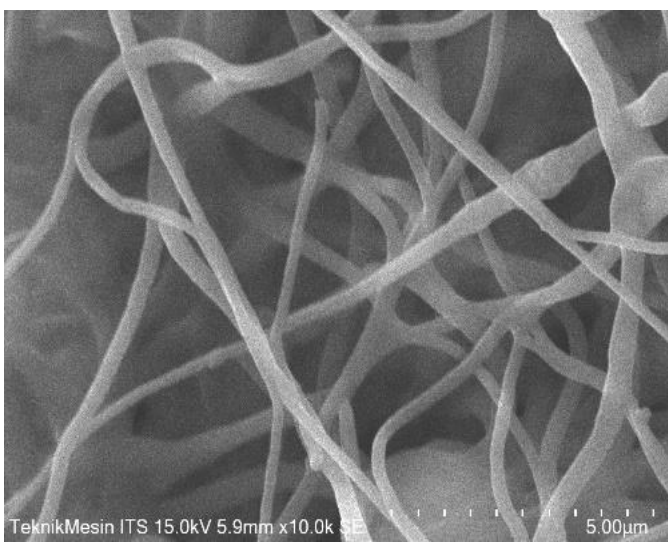

(a)

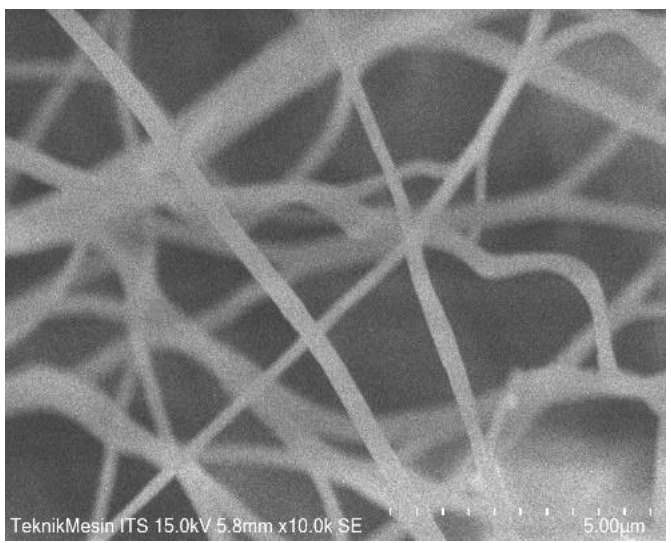

(b)

Figure 5. SEM images of PVA/silicic acid nanofiber mats with (a) 15:0,5\% concentration; (b) 15:1\% concentration.

Table 3.

Electrolyte uptake percentage for PVA/silica-based nanofiber separators

\begin{tabular}{cc}
\hline \hline PVA:silica ratio in nanofiber $(\%)$ & Electrolyte uptake (\%) \\
\hline PVA:silica 15:1 & 151 \\
PVA:silica 15:1,5 & 43 \\
PVA:silica 15:2 & 107 \\
PVA:silica 15:2,5 & 62 \\
PVA:silica 15:3 & 57 \\
\hline \hline
\end{tabular}

Table 4.

Electrolyte uptake percentage for PVA/silicic acid-based nanofiber separators

\begin{tabular}{cc}
\hline \hline PVA:silicic acid ratio in nanofiber $(\%)$ & Electrolyte uptake (\%) \\
\hline PVA:silicic acid 15:0,5 & 132 \\
PVA:silicic acid 15:1 & 146 \\
\hline \hline
\end{tabular}

Table 5.

Electrolyte retention percentage for PVA/silica-based nanofiber separators

\begin{tabular}{ccc}
\hline \hline PVA:silica ratio in nanofiber $(\%)$ & Electrolyte retention $(\%)$ \\
\hline PVA:silica 15:1 & 60 \\
PVA:silica 15:1,5 & 30 \\
PVA:silica 15:2 & 52 \\
PVA:silica 15:2,5 & 38 \\
PVA:silica 15:3 & 36 \\
\hline \hline
\end{tabular}

Table 6.

Electrolyte retention percentage for PVA/silicic acid-based nanofiber separators

PVA:silicic acid ratio in nanofiber (\%) PVA:silicic acid 15:0,5

PVA:silicic acid 15:1

The schematic diagram of the electrospinning apparatus is shown in Figure 1. The electrospinning process was carried out for 6 hours. The resulting nanofibers then were analyzed using scanning electron microscopy (SEM) to determine their morphology characteristics.

\section{Electrolyte Uptake and Retention Test of $\mathrm{PVA} / \mathrm{SiO}_{2}$ Nanofiber}

The electrochemical performance of the $\mathrm{PVA} / \mathrm{SiO}_{2}$ nanofiber related to its application as supercapacitor separator was measured by the electrolyte uptake and electrolyte retention test. Both of these tests were done to investigate the nanofiber capabilities that will affect its ionic conductivity and electrochemical performance. The test was conducted by soaking the nanofiber in $\mathrm{Na}_{2} \mathrm{~S}_{2} \mathrm{O}_{3} 1 \mathrm{M}$ solution for 7 hours. The weight of the nanofiber before and after soaking were measured, and the electrolyte uptake and retention percentage were calculated using the following equations:

$$
\text { electrolyte uptake }(\%)=\frac{w_{w}-w_{d}}{w_{d}} \times 100
$$

Electrolyte retention (\%)

57

59

$$
\text { electrolyte retention }(\%)=\frac{w_{w}-w_{d}}{w_{w}} \times 100
$$

$\mathrm{ww}=$ wet nanofiber weight $(\mathrm{gr})$

$\mathrm{wd}=$ dry nanofiber weight $(\mathrm{gr})$

\section{RESULTS AND DISCUSSION}

\section{A. PVA/Silica Composite Nanofiber Mats}

In making the solution for the electrospinning process, the concentration of PVA is made constant $(15 \% \mathrm{w} / \mathrm{v})$, while the concentration of the silica sol used is varied with concentrations of $0.5,1,1.5,2,2.5$ and $3 \% \mathrm{w} / \mathrm{v}$. In addition to the solution of silica nanoparticles resulting from $\mathrm{KOH}$ titration, silica solution is also used in the form of silicic acid without titration with the $0,5,1$, and $2 \%$ concentration variations. The resulting solution is then put into a $50 \mathrm{ml}$ syringe and then injected into the collector with a syringe pump with a solution flow rate of $0.8 \mathrm{ml} /$ hour. The voltage used is $18 \mathrm{kV}$ and the distance between the tip of the needle and the collector is $15 \mathrm{~cm}$. The electrospinning process lasts 
The $6^{\text {th }}$ International Seminar on Science and Technology (ISST) 2020

July $25^{\text {th }} 2020$, Institut Teknologi Sepuluh Nopember, Surabaya, Indonesia

for 6 hours and the formed nanofiber sheet is peeled from the collector. The results of the experiment of the electrospinning process of PVA/silica solutions can be seen in Table 1 and Table 2.

The physical form of the resulting nanofiber mats can be seen in Figure 2 for some PVA/silica sol variables. While Figure 3 shows the physical form of nanofiber mats for PVA/silicic acid variables. It can be seen that the concentration of the solution of silica sol/silicic acid used affects the resulting nanofiber mats, where at a smaller concentration of silica sol/silicate acid will produce thicker nanofiber mats and fewer dry droplets. This relates to the nature of silica nanoparticles in water, where silica particles have a tendency to undergo aggregation which results in the formation of silica gel. At higher concentrations more silica particles are aggregated so that fewer bonds are formed between the silica particles and the PVA polymer.

From Figure 2 and Figure 3 it can also be seen that at the same time the PVA/silicate acid solution produces nanofiber mats that are thicker and have less dry droplets formed than $\mathrm{PVA} /$ silica. This is related to the composition of silicic acid as silica $\left(\mathrm{SiO}_{2}\right)$ particles which have bonds with hydrogen in water. Silicic acid in water will slowly separate from hydrogen and form silica nanoparticles and release $\mathrm{H}_{2} \mathrm{O}$. This reaction is accelerated by adding $\mathrm{KOH}$ to the solution, but the speed of the formation of silica nanoparticles in this way is difficult to control so that the silica particles formed will tend to easily undergo aggregation which results in gel formation. While in the form of silicic acid this release reaction will take place slowly so that when the PVA polymer is added, the silica particles formed will be more easily bonded with PVA, so that the formed nanofiber mat will be more evenly distributed.

The concentration of silica/silicic acid used also affects the viscosity of the resulting solution, where the higher the concentration of silica/silicic acid used, the resulting solution will be more viscous. This affects the ability of the solution to form fibers in the electrospinning process. From Table 1 and Table 2 it can be seen that at certain silica/silicic acid concentrations the resulting solution cannot form nanofiber mats in the electrospinning process. At $0.5 \%$ silica concentration the solution produced is thinner than the solution with a higher concentration. This can result in the solution being unable to form fibers that are stable at the voltage applied during the electrospinning process, where the dry droplets are formed on the surface of the foil. The opposite occurs in solutions with $2 \%$ silicic acid concentration, where the resulting solution is very viscous. This causes the solution to not form fibers at all when high voltage is applied during the electrospinning process.

The results of SEM analysis for the formed nanofiber mats are shown in Figure 4 and Figure 5. The SEM analysis results in Figure 4 show the morphology of PVA/silica nanofibers at a solution concentration of 15\%:1\% and 15\%:2\%. From the picture it appears that the fiber produced is smoother and there is no visible grain (bead) on the fiber. The average diameter of the nanofiber produced was $334 \mathrm{~nm}$ for a silica concentration of $1 \%$ and $250 \mathrm{~nm}$ for a silica concentration of $2 \%$. It is seen that increasing the concentration of $\mathrm{SiO}_{2}$ decreases the average diameter of the nanofiber produced. This can be due to the repulsive force of $\mathrm{SiO}_{2}$ which limits the joining of the PVA polymer chain, which results in fiber with a smaller diameter [10].

Figure 5 shows the results of SEM analysis for PVA/silicic acid nanofiber mats. It can be seen that the resulting fiber has many curves and for a concentration of $0.5 \%$ there are beads (bead) at a certain point of the fiber. This can be caused by the composition of the silicic acid solution which has more ions than the silica solution. This can affect the stability of the jet that is formed when high voltage is applied to the solution, which causes the resulting fiber to have an irregular arrangement. Increasing the concentration of silicic acid will increase the silica content in the solution which can provide stability when the solution is given a high voltage, which causes the fibers to form more straight and have an average diameter of $328 \mathrm{~nm}$ compared to $207 \mathrm{~nm}$ for the concentration of silicic acid $0,5 \%$.

\section{B. Electrolyte Uptake and Retention Tests of $\mathrm{PVA} / \mathrm{SiO}_{2}$ Nanofiber Mats}

To find out the electrochemical performance of the resulting PVA/silica nanofiber, an electrochemical performance test was carried out in the form of electrolyte uptake and electrolyte retention tests. The electrolyte uptake and retention capacity of a separator will affect the separator's ionic conductivity which is related to its electrochemical performance [10]. The results of electrolyte uptake calculations for each nanofiber variable are shown in Table 3 and Table 4.

From Table 3 it can be seen that the percentage of electrolyte uptake tends to have a downward trend with increasing $\mathrm{SiO}_{2}$ concentrations in nanofibers. As explained before, at higher concentrations of silica particles, the possibility of aggregation will be greater. This can cause the porosity of nanofibers to be reduced, thus affecting its ability as a separator, as shown in Table 3, where the ratio of PVA / silica concentrations of 15:2 to 15:3 nanofibers formed has a lower electrolyte uptake percentage than the concentration ratio of 15:1.

The form of silica components contained in nanofibers can affect the ability of nanofibers as separators. Table 4 shows the percentage of electrolyte uptake for PVA/silicic acidbased nanofiber mats. It can be seen that although the silicic acid solution has more ions than the silica solution, this also causes the $\mathrm{SiO}_{2}$ molecules to have a lower tendency to aggregate, so that the porosity of the nanofibers that are formed tends to increase with increasing concentrations of silicic acid, and resulted in a greater electrolyte uptake percentage. The effect of ion concentration is also found in the variable PVA/silica nanofiber, but its effect on porosity is not as great as the effect of $\mathrm{SiO}_{2}$ aggregation in nanofiber. However, at certain concentrations the effect of ion concentrations can have a greater effect on the nanofibers obtained than the $\mathrm{SiO}_{2}$ aggregation factor. This can explain the value of electrolyte uptake in nanofibers with a PVA: 15: $2 \%$ silica variable which is relatively greater than the following variables. The results of electrolyte retention calculations for each of the nanofiber variables can be seen in 
The $6^{\text {th }}$ International Seminar on Science and Technology (ISST) 2020

July $25^{\text {th }} 2020$, Institut Teknologi Sepuluh Nopember, Surabaya, Indonesia

Table 5 and Table 6 . The percentage of electrolyte retention is related to electrolyte uptake and shows the ability of nanofiber as a separator. From Table 5 and Table 6 it can be seen that each variable shows the same trend of results with the percentage of electrolyte uptake obtained. Where for the $\mathrm{PVA} /$ silica variable, the electrolyte retention value obtained has a tendency to decrease with the increase in the concentration of silica used. This is caused by the tendency for greater aggregation as explained earlier.

\section{CONCLUSION}

PVA/silica nanofiber composites have been successfully manufactured from sodium silicate as silica source using electrospinning method. The formed nanofibers have average fiber diameter of between 200 to $300 \mathrm{~nm}$. The concentration of silica used have an effect on the resulting electrospun nanofibers. The silica concentration also has an effect on the electrochemical performance of the nanofibers, shown by the electrolyte uptake and retention values. The best values obtained are $151 \%$ for electrolyte uptake and $60 \%$ for electrolyte retention, which shows potential for PVA/silica nanofibers as an alternative material for supercapacitor separators.

\section{REFERENCES}

[1] A. González, E. Goikolea, J. A. Barrena, and R. Mysyk, "Review on supercapacitors: Technologies and materials," Renew. Sustain. Energy Rev., vol. 58, pp. 1189-1206, 2016.M. W. Dobson, "VGI as a
Compilation Tool for Navigation Map Databases," in Crowdsourcing Geographic Knowledge, Dordrecht: Springer Netherlands, 2013, pp. 307-327.

[2] K. Liivand, T. Thomberg, A. Jänes, and E. Lust, "Separator Materials Influence on Supercapacitors Performance in Viscous Electrolytes," ECS Trans., vol. 64, no. 20, pp. 41-49, 2015.D. J. Bowersox, D. J. Closs, and M. B. Cooper, Supply Chain Logistics Management, 4th ed. New York: McGraw-Hill, 2013.

[3] N. S. M. Nor et al., "Nanoporous separators for supercapacitor using activated carbon monolith electrode from oil palm empty fruit bunches," AIP Conf. Proc., vol. 1586, no. February, pp. 68-73, 2014.J. Olhager and D. I. Prajogo, "The impact of manufacturing and supply chain improvement initiatives: A survey comparing make-to-order and make-to-stock firms," Omega, vol. 40, no. 2, pp. 159-165, Apr. 2012.

[4] H. Yu et al., "Using eggshell membrane as a separator in supercapacitor," J. Power Sources, vol. 206, pp. 463-468, 2012.

[5] H. Zou, S. Wu, and J. Shen, "Polymer/Silica Nanocomposites: Preparation, characterization, propertles, and applications," Chem. Rev., vol. 108, no. 9, pp. 3893-3957, 2008.M. Cardos, E. Babiloni, M E. Palmer, and J. M. Albarracin, "Effects on undershoots and lost sales on the cycle service level for periodic and continuous review policies," in 2009 International Conference on Computers \& Industrial Engineering, 2009, pp. 819-824.

[6] T. Pirzada, S. A. Arvidson, C. D. Saquing, S. S. Shah, and S. A. Khan, "Hybrid Silica - PVA Nanofibers via Sol - Gel Electrospinning," 2012.

[7] L. Ji and X. Zhang, "Ultrafine polyacrylonitrile/silica composite fibers via electrospinning," Mater. Lett., vol. 62, no. 14, pp. 2161-2164, 2008.

[8] S. Ramakrishna, K. Fujihara, W. Teo, T. Lim, and Z. Ma, An Introduction to Electrospinning and Nanofibers. 2005.

[9] A. Freyer and N. O. Savage, "Electrospun silica nanofiber mats: Effects of sol viscosity and application to thin layer chromatography," ACS Symp. Ser., vol. 1183, pp. 139-150, 2014.

[10] M. Yanilmaz, "Evaluation of electrospun PVA / $\mathrm{SiO}_{2}$ nanofiber separator membranes for lithium-ion batteries," J. Text. Inst., vol. 0, no. 0, pp. 1-6, 2019. 